upon which the series of lectures should be framed. You will probably deem it right that the subject should be dealt: with upon elementary lines; indeed, you may regard this: as necessary. I take leave to think that most of you possess no acquaintance with military affairs; that the constitution of, say, an army corps is unknown to you; that its allotment of divisions and brigades are mere names to you; that the proceedings adopted to call into existence the machinery for mobilizing a force for the fieldi. and especially what part the medical branch plays in these things and these proceedings are also matters with which you cannot be expected to be familiar.

Perhaps you will allow me to recapitulate the present position of the medical corps in relation to the problem of efficiency, and to emunciate the principles upon which we have, as the phrase goes, reorganized the medical service. In the front rank we place professional efficiency, and the means of attaining it. We desire to adapt to our purposes the resources of modern science; and for this reason we desire a close connexion with the profession, and we have, as I think, successfully endeavoured to raise the standard of work in our large institutions. We have borne in mind that to raise the standard of work we have to provide for the training of the subordinate personnel more than for that of the medical officers. I think I can say that we have encouraged medical officers and matrons to improve the method of training of our men, and that we endeavour to allocate to all ranks the class of work which the individuals prefer or for which they are best suited. In this direction we claim to have grasped the most important factor determining efficiency: The army medical officer, like every member of the profession, has his special preferences.

In the series of lectures which are to follow you will become acquainted with the details of medical organization in peace and war. Should the occasion ever arise when it may be possible for you, busy men as you are, to take a part in the great work, $I$ cannot doubt that you will be the more useful to the army because of a little preliminary education.

\section{Climital hemarks}

ON A

\section{Case OF TUBerculous Disease. OF' THE LUNGS AND LARYNX,}

SHOWING THE NEED FOR THE OOMPULSORY NOTIFICATION OF PHTHISIS.

BY. BYROM BRAM WELL, M.D., F.R.C.P.FD, PHYSICIAN TO THE ROYAL INFIRMARY, EDINBURGH.

Gentlemen,-This girl, aged: 21 , is a kitchenmaid. She is suffering from tuberculous disease of the lungs and larynx. She was in the hospital in March last, and was treated for some time by the open-air treatment (on the balcony). The sputum was teeming with tubercle bacilli I have never seen any case in which. they were more numerous; great clumps of bacilli, in addition to innumerable isolated bacilli, were scattered abundantly throughout the sputum.

When the patient discharged herself she told me that it was her intention to take a situation as a kitchenmaid in a public institution. I told her that she must not think of doing this. I seriously warned her that it would be very wrong to do so-that: it would be dangerous to other people.

Well, we lost sight of her for some months. She applied for readmission a few days ago. Her condition is very much the same as it was in March; the lungs and larynx are extensively diseased; the sputum still contains large numbers of tubercle bacilli, though not the great clumps which were present when she was in the hospital before ; the large clumps of tubercle bacilli were probably due to the breaking down and evacuation of tuberculous deposits in the larynx. The patient tells me that, notwithstanding my advice, immediately after her discharge in March she applied for and obtained a situation as kitchenmaid in an eating house. She says that the staff consisted of six in the kitchen and nineteen in the shop it was, therefore, a very large establishment. The cus- tomers must have been very numerous to keep such a large staff employed.

Observe the danger of such a state of matters-a girl whose sputum was literally teeming. with. tubercle bacilli; employed as kitchenmaid in a public eatinghouse which supplied food to a very large number of customers daily!

A case like this shows the necessity of the public supervision of cases of phthisis. Some seven years ago I published a long and elaborate article on the compulsory notification of phthisis, ${ }^{2}$ and I think conclusively showed the advisability, nay, the necessity, of such a measure, if a real and serious attempt is to be made to eradicate this terrible disease.

In that article and in a series of lectures which were subsequently published in the Lancet, I exhaustively considered the arguments in favour of and against a system of compulsory notification specially adapted for phthisis. It is obvious that unless you know where the cases of phthisis are located you cannot take the proper and necessary measures to limit the spread of the infection. At that time (1899) the profession in this country would not listen to the proposal; it is not, I think, an exaggeration to say that it was received with a very cold shoulder by almost everyone. People could not be made to see that compulsory notification, as applied to phthisis, carries with it quite different results, in the way of preventive measures, from the preventive measures (isolation, removal to a hospital, etc.) which are required in the case of the ordinary contagious and infectious diseases (scarlet fever, small-pox, typhus, etc.).

Further consideration of the subject has made me more convinced than ever that compulsory notitication is essential, if a real and serious effort is to be made to eradicate the disease. This opinion is now strongly held by Koch and many other leading authorities. There are I think, indications that this opinion is' gradually gaining ground in this country; but we are still very much behindhand, far too conservative in this matter. The Americans take a very much more enlightened. view of this question than we do; the compulsory notification. of phthisis has been widely adopted in the United States of America. In a recent letter, $\mathrm{Mr}$. William $\mathrm{H}$. Baldwin of Washington tells me that already in more than half of the cities in the United States with a population of over $48,0.00$, such a law has been passed, and is more or less thoroughly enforced. He also states that in the great majority of cases the reports are kept private, and that there is no difficulty in keeping them private. Now if the compulsory notification of phthisis has been adopted and works well in America, there is no reason why it should not be adopted and why it should not work well here.

The case which I have brought before your notice this morning shows in a very forcible way the necessity for such a measure. If this case had. been. under proper medical supervision, this patient would never have been allowed to act as a kitchenmaid in a public eating-house. Further, means would have been taken to see that she disinfected her sputum. The prevention of phthisis is a very simple matter in comparison with the prevention of many of the contagious and infectious diseases. In phthisis, isolation and removal to hospital are not called for except in a comparatively small number of what I term dangerous cases. Most patients affected. with phthisis may be allowed to mix with their fellows and to follow their ordinary occupations. What is required is the destruction or thorough disinfection of the sputum. Now, unless you know where the cases of phthisis are located, you cannot see that they are properly instructed in respect to the measures which slould be adopted for the destruction or disinfection of the sputum, and you cannot see (even if they have the knowledge) that they are habitually practising the comparatively easy and simple measures which are necessary: for destroying the poison and preventing its dissemination; in other words, for preventing the spread of the disease to other people. It would be hazardous to speculate as to the number of people to whom this patient may have been the means of communicating the disease in other words, how many cases of phthisis might have been prevented if, by means of a proper system of compulsory notiffeation' and supervision, this patient lyad been rendered innocuous as a disseminator of the poison (the tubercle bacilli). I do not of course mean to suggest that 
the introduction into the stomach of food carrying the tubercle bacillus is a usual method of infection, but it certainly is a possible method. There can be no doubt that a kitchenmaid whose sputum is teeming with tubercle bacilli might be a source of serious danger to the other women working alongside of her, and no one will, I suppose, say that $a$ person whose sputum is teeming with tubercle bacilli should be allowed to prepare the food for a public eating-house.*

\section{OCliniral (Obartuations}

$$
\text { oN }
$$

\section{SOME ACUTE ABDOMINAL DISORDERS}

\author{
WHICH RESEMBLE IN THEIR SYMPTOMS \\ ACUTE INTESTINAL OBSTRUCTION. \\ READ BEFORE THE BIRMINGHAM BRANCH OF THE \\ BRITISH MEDICAL ASSOCIATION, \\ JANUARY 11TH, 1906.

\section{By GEORGE HEATON, M.B., F.R.C.S.,} \\ SURGEON, BIRMINGHAM GENERAL HOSPITAL.
}

Acute intestinal obstruction is a surgical emergency of extreme gravity, and measures for its relief, if they are to be successful, must be undertaken with the least possible delay. The intestinal walls are so delicate and their nervous supply so intricate that any interference with their vascular supply, or with the free flow of their contents along them, in a short while may produce such grave pathological changes as almost to preclude restoration of their functions, even though the cause of such changes be removed.

It is for these reasons that the urgency of a rapid and accurate diagnosis is so great. It is not possible, as in so many disorders, to " watch the case" and by its progress endeavour to arrive at its true nature. For treatment, if it is to be effective, must be prompt. The mortality of delayed operations for obstruction is so high that we musts train every nerve to effect relief at the earliest possible moment.

Unfortunately for the diagnostician, intestinal obstruction is, in its early stages, simulated very closely by a variety of disorders and ailments. In fact, in some cases an accurate diagnosis is impossible, and one must adopt measures based upon what is at the most but a tentative opinion rather than run the risk of allowing an acute obstruction to remain unrelieved.

For these reasons mistakes in diagnosis will not infrequently occur; nay, by the very nature of things, are bound to occur when diagnosis has to be so hurried and active treatment has so quickly to follow upon it. Personally, I always view with some distrust my own diagnosis of any internal disorder when given after a single-and, it may be, brief-examination, and would always, if possible, have a patient under observation, if only for a brief period, before operating. But in these (ases this is seldom practicable, and, consequently, errors of diagnosis more frequently creep in here than in any other class of case.

Disorders Simulating Intestinal Obstruction.

I wish now to allude to a number of abdominal disorders which give rise to symptoms closely simulating those of intestinal obstruction, and are easily mistaken for it, feeling sure that it is only by such study that we can hope to avoid.pitfalls.

When a coil of intestine has undergone any form of strangulation, its blood supply is suddenly interfered with, and its delicate nervous mechanism injuriously pressed upon. A certain train of symptoms is set up, characterized 7) acute abdominal pain with collapse and severe vomiting. These symptoms are due to the sudden painful impression of the strangulation on the sensitive sympathetic nervous system of the abdomen.

* I hope all my readers will make a careful study of this question (compulsory notification as applied to phthisis), and, if they are convinced of its advisability, do what they can to educate medical aud lay opinion, so that we may in this country before long follow the culighteued example of the United States.
The term "peritonism" has been coined, I believe, by Sir F. Treves for this condition. It is always present in $\mathbf{a}$. greater or less degree at the commencement of an acute obstruction, and the patient may actually die in this state of collapse.

But it must be remembered that the same train of symptoms may be produced by many other acute abdominal disorders, such as the perforation of a hollow viscus like the stomach, the occlusion of a mesenteric vessel, the rotation of an ovarian cyst, or the rupture of an intraperitoneal abscess; and it is only by an accurate history of the events leading up to the sudden illness (in the patient's previous history) and a close study of his physical signs and symptoms as they develop, that we can differentiate between the various causes of the condition.

Symptoms of Acute Intestinal Obstruction.

The typical cardinal symptoms of acute intestinal obstruction may be briefly summed up as follows:

1. Sudden violent abdominal pain usually at the umbilicus or in the epigastrium. This pain is usually colicky in character, subject to violent exacerbation, and is sometimes relieved by pressure.

2. Collapse accompanies the onset of the pain, with pallor of the face and extremities and a small, thready pulse.

3. Vomiting occurs, first of all of the contents of the stomach, and then as the case proceeds the vomited matter becomes more and more stercoraceous in character.

4. Absolute constipation.

5. A subnormal temperature is usually present throughout, unless peritonitis supervenes.

The abdomen is as a rule soft and flaccid at the beginning, but becomes distended and tympanitic as the case proceeds.

The sunken eye and pinched face soon show themselves, and point to the severity of the abdominal lesion The patient rapidly becomes worse; and soon the pulse begins to fail, increasing rapidly in frequency and diminishing in volume until death finally occurs from asthenia and septic poisoning, the temperature frequently remaining subnormal and consciousness being retained until the last.

The conditions which most closely simulate such a case are as follows :

1. Biliary or renal colic.

2. Perforative peritonitis due to the rupture of a gastric or duodenal ulcer.

3. Gangrenous appendicitis or the rupture of an appendical abscess.

4. Tuberculous peritonitis.

5. Acute haemorrhagic pancreatitis.

6. Torsion of an undescended testicle or rotation of an ovarian cyst.

7. Rupture of an ectopic gestation sac.

8. Embolism or thrombosis of the superior mesenteric vessels.

\section{Biliary or Renal C'olic.}

Of biliary and renal colic I do not propose to say anything. There is often a history of previous similar attacks, which have been followed by jaundice or the passage of blood in the urine. The pain is not so general and is localized, as a rule, to the region of the gall bladder or the loin. The symptoms at the actual onset may be somewhat alarming, but as a rule the collapse is not so severe as in intestinal obstruction, and passes off in a few hours.

Perforation of Gastric or Iuodenal Ulcer.

When a gastric or duodenal ulcer perforates the collapse is usually extreme. At the moment of rupture there is often a feeling of something having given away-several of the patients with ruptured gastric ulcer on whom I have operated liave told me that at the moment of onset of their illness they felt a burning pain in the epigastrium as if something hot were being poured out-and the pain and tenderness are most marked high up in the epigastric region.

The history of the case is usually of great help. A gastric ulcer seldom perforates which has not already given evidence of its existence. The patient has usually had epigastric pair and tenderness, increased by taking food, for a considererable time before, vomiting, and in many cases, attacks of hematemesis.

In two cases of duodenal ulcer which have been under my notice there was a history of occasional transient jaundice in addition to these attacks of indigestion. 